\title{
Influence of Dietary Riboflavin Deficiency on Lenticular Glutathione Redox Cycle, Lipid Peroxidation, and Free Radical Scavengers in the Rat
}

\author{
P. Vasanth RAO and K. Seetharam BHAT* \\ National Institute of Nutrition, Indian Council of \\ Medical Research, Jamai Osmania P.O., \\ Hyderabad-500 007, India
}

(Received February 24, 1989)

\begin{abstract}
Summary Effect of dietary riboflavin deficiency on rat lens glutathione, glutathione redox cycle, and oxidative-antioxidative processes was investigated to understand the possible biochemical mechanism(s) responsible for aggregation of lens proteins. Induction of riboflavin deficiency resulted in a marked reduction in the activity of glutathione reductase (GSH-R). Levels of glutathione (both reduced and oxidised) and sulfhydryl groups (total and non-protein), however, were unchanged. Activity of glucose 6-phosphate dehydrogenase, which generates the reducing equivalents, NADPH, necessary for maintenance of normal GSH-R activity, was found to be unaltered. On the other hand, glutathione dependent glutathione peroxidase, a potent peroxide scavenging enzyme, showed a significant rise in its activity with a concomitant increase in lipid peroxidation. Among the other antioxidative systems studied, superoxide dismutase and catalase remained unaltered, while levels of ascorbate declined.

These results indicate impairments in the glutathione redox cycle and antioxidative defence mechanisms, in addition to enhanced lipid peroxidation in the lens of riboflavin deficient rats.
\end{abstract}

Key Words: rat lens, riboflavin deficiency, oxidant-antioxidant system, aggregation of proteins

The most frequent cause of blindness in the world is opacification of the eye lens or cataract. It is known that a combination of risk factors, among which riboflavin deficiency has also been implicated, play a role in the development of cataract $[1-3]$.

*To whom correspondence should be addressed. 
In a recent study, Bhat [4] has shown that there was a significant increase in the proportion of high molecular weight (HMW) protein (with a concomitant decrease in $\gamma$-crystallins) in riboflavin-deficient rat lens. Although these results suggest an increased aggregation of proteins, the underlying biochemical mechanisms for this as well as lenticular opacity are not fully delineated in riboflavin deficiency.

Flavin adenine dinucleotide (FAD), the coenzyme form of riboflavin, is needed for the activity of glutathione reductase (GSH-R), which plays a pivotal role in the oxidant antioxidant balance by maintaining normal levels of reduced glutathione $(\mathrm{GSH})[5,6]$. Since, riboflavin deficiency often leads to reduced GSH-R activity in various tissues including lens [7-9] and subsequent disturbances in the antioxidant system can lead to aggregation of lens proteins $[5,6]$, in the present study an attempt has been made to unravel the possible significance of various defence systems against oxidant stress in riboflavin deficiency.

\section{MATERIALS AND METHODS}

Materials. NADP, NADPH, FAD, oxidized glutathione (GSSG), GSH, N-ethylmaleimide (NEM), orthophthalaldehyde (OPT), glucose 6-phosphate disodium salt, 5,5'-dithio-bis(2-nitrobenzoic acid) (DTNB), nicotinamide, $\mathrm{NaN}_{3}$, tert-butyl hydroperoxide, pyrogallol (trihydroxybenzene), diethylenetriaminepentaacetic acid, 2-thiobarbituric acid, 1,1,3,3-tetraethoxypropane, ascorbic acid, and GSH-R (EC 1.6.4.2) were purchased from Sigma Chemical Co., St. Louis, MO, USA. All other chemicals were of analytical grade.

Test animals. Three sets of experiments were performed. Twenty three day-old weanling male albino rats of Wistar-NIN strain were distributed into each of three dietary regimens [10] using a randomized block design: 1) riboflavin supplemented, fed ad libitum; 2) riboflavin deficient, fed ad libitum; 3) riboflavin supplemented pair-fed with the riboflavin-deficient rats. In brief, the riboflavindeficient diet contained $(\mathrm{g} / \mathrm{kg})$ : vitamin-free casein, 200; sucrose, 700; groundnut oil, 50; mineral mixture, 40; vitamin mixture (riboflavin omitted), 6; and choline chloride, 4; $8 \mathrm{mg}$ of riboflavin was added to the diet which was fed to the riboflavin-supplemented groups. Rats were housed individually in screenbottomed cages maintained at $22-25^{\circ} \mathrm{C}$ and exposed to $12-\mathrm{h}$ light-12-h dark cycles. All animals were periodically examined for ocular changes by slit lamp microscopy (Kowa portable SL5, hand held slit lamp, Kowa Co. Ltd., Japan) after dilation of the pupil with $1 \%$ atropine sulfate (1-2 drops). At the end of 75 days of feeding, rats were decapitated by guillotine after overnight fasting. Lenses were excised through posterior approach. Lenses from 2-3 rats were pooled and a $10 \%$ homogenate (ice-cold) was prepared in either $0.2 \mathrm{M}$ Tris-EDTA buffer, pH 8.2 (first set of animals) or $0.05 \mathrm{M}$ sodium phosphate buffer, pH 7.2 (second set of animals) using a Potter/Elvehjam glass homogenizer. A $7.5 \%$ homogenate was prepared from two lenses (third set of animals) in 5\% ice-cold TCA. Aliquots of 
the lens homogenate (Tris-EDTA buffer) were analysed for GSH and GSSG measured fluorimetrically [11] in a Hitachi 650-10S spectrofluorimeter and for total and non-protein sulfhydryl groups with Ellman's reagent [12]. Lipid peroxide level was estimated (in terms of malondialdehyde (MDA)) in the phosphate buffer by the thiobarbituric acid (TBA) reaction [13] and ascorbic acid in 5,000 $\times$ $g$ supernatant of 5\% TCA homogenate, using orthophosphoric acid, ferric chloride and $\alpha \alpha^{\prime}$-dipyridyl [14].

The remaining homogenate (Tris-EDTA buffer) was centrifuged at $20,000 \times$ $g$ in a Sorvall RC5B super-speed centrifuge at $4^{\circ} \mathrm{C}$ for $30 \mathrm{~min}$. The $20,000 \times g$ supernatant was used for the assay of glutathione redox cycle enzymes. Glucose 6-phosphate dehydrogenase (G6PDH) was assayed spectrophotometrically as described by Selvaraj, and Bhat [15]. The reaction mixture contained in $1.2 \mathrm{ml}: 50$ $\mu \mathrm{mol}$ glycylglycine buffer ( $\mathrm{pH} 8.7$ ), $12 \mu \mathrm{mol} \mathrm{KCl}, 12 \mu \mathrm{mol} \mathrm{MgCl}_{2}, 3 \mu \mathrm{mol}$ nicotinamide, $6 \mu \mathrm{mol}$ glucose 6-phosphate, and $75 \mu 1$ lens tissue supernatant. The reaction was started by adding $0.12 \mu \mathrm{mol} \mathrm{NADP}{ }^{+}$. GSH-R was assayed by the method of Bayoumi, and Rosalki [16] as described elsewhere [9]. Glutathioneperoxidase (GSH-PX) was assayed as described by Hochstein and Utley [17] with the following modification: The reaction mixture contained in $1 \mathrm{ml}: 50 \mu \mathrm{mol}$ phosphate buffer (pH 7.2), $2.5 \mu \mathrm{mol} \mathrm{GSH}, 0.5 \mu \mathrm{mol} \mathrm{NaN}_{3}, 0.3 \mu \mathrm{mol}$ EDTA, 0.1 $\mu \mathrm{mol}$ NADPH, 0.5 IU GSH-R, and $75 \mu$ l supernatant (enzyme preparation, $1: 5$ dilution). The reaction mixture was incubated at $37^{\circ} \mathrm{C}$ for $10 \mathrm{~min}$ and the reaction started by the addition of $0.25 \mu \mathrm{mol}$ tert-butyl hydroperoxide. Catalase in the $750 \times g$ supernatant fraction of the homogenate prepared in phosphate buffer was assayed polarographically as described by Goldstein [18] with a polarograph (YSI, Model 5301) equipped with an oxygen monitor (model 53) and a recorder (LKB 2210). The activity of superoxide dismutase (SOD) in supernatant fractions of the lens homogenate (phosphate buffer) obtained by centrifugation at $35,000 \times \mathrm{g}$ and $0-4^{\circ} \mathrm{C}$ for $25 \mathrm{~min}$ was determined spectrophotometrically by measuring the inhibition of autooxidation of pyrogallol [19]. Protein concentration was measured by the method of Lowry et al. [20].

Statistical analysis. The data was analysed by one way analysis of variance. The mean differences were also further tested by Duncan's multiple range test.

\section{RESULTS}

This study spans three different animal experiments in every one of which riboflavin-deficient rats showed a severe growth retardation, hair loss, and skin lesions, all of which are characteristic features of riboflavin deficiency.

Ocular examination revealed severe corneal vascularization in riboflavindeficient rats (30\%) as compared to control rats. However, slit-lamp microscope examination of the eyes revealed that most of the riboflavin-deficient rat lenses were clear with the exception of $3 \%$ of these animals, which exhibited transient appearance of anterior capsular and anterior cortical opacity including the ' $Y$ ' 
suture, at the end of 50 days of feeding. Also, one (1.5\%) riboflavin-deficient rat did develop mature cataract in both eyes.

The lens wet weight and protein concentration of riboflavin-deficient and control rats were similar to those reported earlier [9].

Table 1 summarizes the differences in the activities of lens GSH-R, GSH-PX, G6PDH, activity coefficient of GSH-R, and the ratio of GSH-PX/GSH-R between riboflavin-deficient and control rats. The basal activity (in the absence of added cofactor, FAD) of GSH-R was significantly decreased $(p<0.001)$ in riboflavindeficient rat lenses, being 38 and $46 \%$ lower than values in pair-fed and ad libitum control groups lenses, respectively. While the enzyme activity assayed after the (in vitro) addition of FAD was not found to be significantly different among the three groups (data not given), it emerged that the activation coefficient of GSH-R, which is commonly used as an index of riboflavin nutritional status $[9,10,21]$ was increased significantly $(p<0.001)$ in riboflavin-deficient rats as compared with that of the controls. The activity of G6PDH was not significantly different among the 3 groups of rats studied. GSH-PX activity in riboflavin-deficient rats was significantly $(p<0.05)$ increased when compared with those in both ad libitum and pair-fed control rats. The mean value for the ratio of GSH-PX/GSH-R in riboflavin-deficient rat lens was significantly increased $(p<0.001)$ as compared with those of the pair-fed and ad libium control lenses.

As shown in Table 2, levels of glutathione (both GSH and GSSG) and

Table 1. Lens glutathione redox cycle enzyme activities in riboflavin-deficient and control rats.

\begin{tabular}{|c|c|c|c|}
\hline & $\begin{array}{l}\text { Ad libitum } \\
\text { control (9) }\end{array}$ & $\begin{array}{l}\text { Riboflavin- } \\
\text { deficient (7) }\end{array}$ & $\begin{array}{c}\text { Pair-fed } \\
\text { control (9) }\end{array}$ \\
\hline Glutathione reductase $^{\mathrm{a}}$ (GSH-R) & $2.4 \pm 0.07$ & $1.3 \pm 0.09 * *$ & $2.1 \pm 0.07$ \\
\hline Activation coefficient of GSH-R ${ }^{b}$ & $1.19 \pm 0.045$ & $1.97 \pm 0.140^{* *}$ & $1.25 \pm 0.051$ \\
\hline $\begin{array}{l}\text { Glucose 6-phosphate } \\
\text { dehydrogenase }\end{array}$ & $8.0 \pm 0.60$ & $7.8 \pm 0.62$ & $8.3 \pm 0.60$ \\
\hline Glutathione peroxidase ${ }^{\mathrm{a}}$ (GSH-PX) & $24.4 \pm 0.86$ & $30.1 \pm 1.23^{*}$ & $25.4 \pm 0.95$ \\
\hline GSH-PX/GSH-R radio & $10.2 \pm 0.27$ & $23.8 \pm 1.74^{* *}$ & $12.2 \pm 0.56$ \\
\hline
\end{tabular}

Table 2. Effect of riboflavin deficiency on lens glutathione and sulfhydryl groups.

\begin{tabular}{lccc}
\hline $\begin{array}{l}\text { Parameters }(\mu \mathrm{mol} / 100 \mathrm{mg} \\
\text { lens wet weight) }\end{array}$ & $\begin{array}{c}\text { Ad libitum } \\
\text { control }(9)\end{array}$ & $\begin{array}{c}\text { Riboflavin- } \\
\text { deficient (7) }\end{array}$ & $\begin{array}{c}\text { Pair-fed } \\
\text { control (9) }\end{array}$ \\
\hline GSH & $1.23 \pm 0.146$ & $1.27 \pm 0.156$ & $1.35 \pm 0.121$ \\
GSSG & $0.16 \pm 0.025$ & $0.16 \pm 0.020$ & $0.16 \pm 0.021$ \\
Total sulfhydryl groups & $5.4 \pm 0.15$ & $5.4 \pm 0.16$ & $5.6 \pm 0.26$ \\
Non-protein sulfhydryl groups & $0.37 \pm 0.020$ & $0.43 \pm 0.020$ & $0.42 \pm 0.016$ \\
\hline
\end{tabular}

Values are mean \pm SEM. Numbers in the parentheses indicate sample size. 


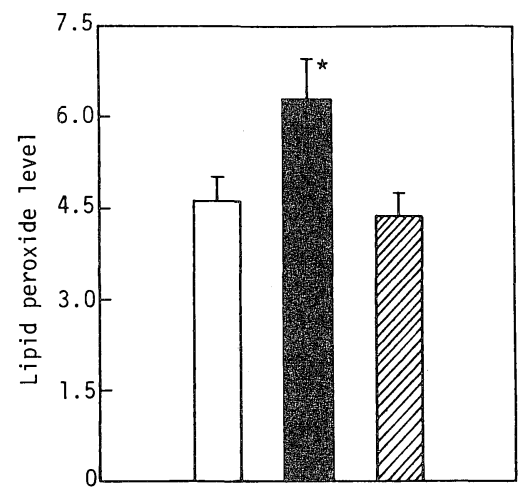

Fig. 1. Effect of riboflavin deficiency on lens lipid peroxide levels. Lipid peroxide level was determined by TBA reaction and expressed as nmol malondialdehyde/g lens weight.

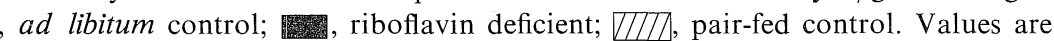
mean \pm SEM, $n=9-10$. *Significantly different $(p<0.05)$ compared with control groups.

Table 3. Changes in the activities of lens catalase and superoxide dismutase and in ascorbic acid levels in riboflavin-deficient and control rats.

\begin{tabular}{|c|c|c|c|}
\hline & $\begin{array}{l}\text { Ad libitum } \\
\text { control }\end{array}$ & $\begin{array}{c}\text { Riboflavin } \\
\text { deficient }\end{array}$ & $\begin{array}{l}\text { Pair-fed } \\
\text { control }\end{array}$ \\
\hline Catalase $^{\mathrm{a}}$ & $\begin{array}{c}0.94 \pm 0.077 \\
(10)\end{array}$ & $0.90 \pm 0.104$ & $\begin{array}{c}0.84 \pm 0.119 \\
(10)\end{array}$ \\
\hline Superoxide dismutase ${ }^{\mathrm{b}}$ & $\begin{array}{c}40.9 \pm 1.49 \\
(10)\end{array}$ & $\begin{array}{c}41.6 \pm 1.26 \\
(8)\end{array}$ & $\begin{array}{c}43.9 \pm 1.81 \\
(10)\end{array}$ \\
\hline $\begin{array}{l}\text { Ascorbic acid } \\
\qquad(\mu \mathrm{g} / \mathrm{g} \text { lens wt })\end{array}$ & $\begin{array}{c}49.5 \pm 2.25 \\
(9)\end{array}$ & $\begin{array}{c}39.0 \pm 2.21^{*} \\
(9)\end{array}$ & $\begin{array}{c}48.5 \pm 2.48 \\
(9)\end{array}$ \\
\hline
\end{tabular}

sulfhydryl (total and non-protein) groups were found to be unaltered between riboflavin-deficient and control lenses.

Thiobarbituric acid reactive substances in the lens and changes in their concentration between riboflavin-deficient and control rat lenses are illustrated in Fig. 1. It is evident from the figure that the lipid peroxide levels were increased significantly $(p<0.05)$ in riboflavin-deficient rat lenses when compared with those in pair-fed and ad libitum control lenses.

The results presented in Table 3 indicate that the activities of lens catalase and SOD were found to be unaltered among the 3 groups of rats. In riboflavin-deficient rat lenses, the ascorbic acid levels were decreased significantly $(p<0.01)$ as compared with those in pair-fed (22\%) and ad libitum (21\%) control rats. 


\section{DISCUSSION}

Oxidation of crystallins and membrane components has long been recognised to be an early fundamental change in the cataractous lens $[6,22]$. Such changes often result in aggregation of lens protein which eventually leads to lens opacity [22]. Potentially reactive oxidants such as superoxide $\left(\mathrm{O}_{2}{ }^{-}\right)$, singlet oxygen $\left({ }^{1} \mathrm{O}_{2}\right)$, hydrogen peroxide $\left(\mathrm{H}_{2} \mathrm{O}_{2}\right)$, lipid peroxides $(\mathrm{ROOH})$, and hydroxyl radicals $(\cdot \mathrm{OH})$ can be formed in the cell through metabolic and photochemical reactions mediated by univalent reduction of oxygen [23]. These reactive species of oxygen could be triggering oxidants in the initiation of cataract formation [24]. However, the lens contains a series of protective mechanism against these deleterious oxidants. These include enzymatic ones: SOD, catalase, GSH-PX, and GSH-R as well as non-enzymatic: GSH, ascorbic acid and tocopherol $[5,6,25]$.

In the present study, GSH-R, which reduces GSSG to GSH and mediates the release of GSH from protein-GSH mixed disulfides [26] was decreased markedly in riboflavin deficiency. This finding conforms with our earlier observation [9] and with those of many others [7,8].

The activity of GSH-PX, which oxidises GSH to GSSG in the presence of peroxides, was found to be increased significantly during riboflavin deficiency. Thus, the increased GSH-PX together with lowered GSH-R should have enhanced oxidation of GSH. However, surprisingly both GSH and GSSG were found to be normal. This suggests that the remaining GSH-R with normal hexose monophosphate (HMP) shunt activity (as evidenced by normal G6PDH activity) can maintain normal GSH levels. Taken together, the data on GSH-R, GSH-PX, G6PDH activities and GSH-PX/GSH-R ratio suggest that the flux of GSH/GSSG may be altered in riboflavin deficiency. While it is considerably difficult to verify such a proposition by direct experimentation, it is of interest to note that there was an increase in lipid peroxide levels. The values for GSH levels in rat lens in the present study appear to be higher compared with those reported in literature [27]. This would be perhaps due to difference in methodology used by different investigators. However, our values stand in good agreement with those $(1.16 \pm 0.136$ $\mu \mathrm{mol} / 100 \mathrm{mg}$ lens) reported by Horiuchi et al. [28]. Our observation of normal GSH levels in riboflavin deficiency is in agreement with that reported by Srivastava, and Beutler [7] in the lens. A similar observation was also reported for erythrocyte GSH levels and HMP shunt [29, 30]. However, Horiuchi et al. [28] reported lowered GSH and increased GSSG in conjunction with lowered GSH-R activity in riboflavin-deficient rat lenses. The reasons for this difference is not clear at present. However, Rogers and Augusteyn [31] have suggested that a small amount of GSH-R activity could maintain normal GSH levels even in cataractous lenses. It is also possible that this difference could be due to differences in the strains of rats used.

Normal levels of sulfhydryl groups observed in riboflavin-deficient rats in this

J. Clin. Biochem. Nutr. 
study rule out the possibility of enhanced oxidation of sulfhydryl groups, suggesting that the accumulation of HMW protein in riboflavin deficiency reported earlier [4] may not be due to excessive disulfide cross-linking in crystallines. This observation is again in agreement with the study of Srivastava and Beutler [7]. Aggregation of lens proteins in cataract etiology has long been regarded to be the consequence of sulfhydryl oxidation $[6,22]$. Indeed in many types of cataracts, lens opacity and decrease in sulfhydryl groups were often, but not always, found to correlate satisfactorily. However, in some cataracts (traumatic and genetic) sulfhydryl oxidation may not be an essential factor in the insolubilization of lens proteins [32].

Glutathione peroxidase, a seleno protein, is the major peroxide-scavenging enzyme present in the lens. It has been thoroughly characterised, and this enzyme activity was increased significantly in riboflavin-deficient rat lenses as compared with that in vitamin-supplemented rat lenses. This is in variance with the result observed by Hirano et al. [33]. In several experimental studies, increased GSH-PX activity has been demonstrated in conjunction with increased oxidative stress [34] and its role in inhibiting lipid peroxidation is a well acknowledged one [35]. Therefore, the elevated GSH-PX activity in riboflavin deficiency could be an adaptive response to oxidative stress. This observation is in agreement with that of Taniguchi, and Hara [36], who found increased GSH-PX activity in parallel with increased lipid peroxidation in riboflavin-deficient rat liver. In several in vitro studies using 1,3-bis(2-chloroethyl)-1-nitrosourea, (a specific inhibitor of GSH-R) increased susceptibility of lens to oxidative stress has been demonstrated [5]. Thus, the lowered GSH-R activity co-existing with increased GSH-PX activity in riboflavin deficiency is suggestive of enhanced oxidative stress.

In this study, riboflavin deficiency caused an increase in lipid peroxide levels. While this work was in progress, Hirano et al. [33] also reported similar observations in riboflavin-deficient rat lens. Lipid peroxidation products have been implicated in cataract formation [25, 37], and malondialdehyde (MDA), a bifunctional protein cross-linking agent has been implicated in protein aggregation [38]. Further, Bhuyan et al. [39] have recently isolated MDA-protein cross-linked products from human cataractous lenses. Therefore, it is reasonable to speculate that enhanced lipid peroxide levels observed here in riboflavin deficiency could be partly responsible for the accumulation of HMW proteins reported earlier [4]. Since lipid peroxides are substrates of GSH-PX [40], the increased lipid peroxidation in riboflavin deficiency could also be responsible for the increased GSH-PX activity. Enhanced lipid peroxidation, in conjunction with increased GSH-PX activity in riboflavin-deficient lenses, clearly supports the view that riboflavin deficiency leads to enhanced oxidative stress.

Although the reasons for this increased lipid peroxidation are not clear presently, among the other antioxidative systems (involving ascorbic acid, catalase, and SOD) studied in riboflavin deficiency, ascorbate levels registered a significant decline. Ascorbic acid is one of the important antioxidant defence systems of the 
lens and is present in very high concentrations in lens and aqueous humour [41]. Ascorbic acid has been demonstrated to be a potent scavenging agent of singlet oxygen [42] and superoxide [43]. Lowered ascorbic acid levels are commonly associated with cataract formation $[6,25,41]$. Therefore the lowered ascorbic acid in riboflavin deficiency could be partly responsible for enhanced lipid peroxidation. Though the mechanism for decreased ascorbic acid levels in riboflavin deficiency cannot be stated definitely, either the lowered GSH-R activity together with enhanced GSH-PX/GSH-R ratio may be responsible [6] or there may be an impairment in its biosynthesis [44].

Activities of lens catalase and SOD were found to be normal in riboflavin deficiency (Table 3). These changes suggest that the enzymatic mechanisms for scavenging $\mathrm{H}_{2} \mathrm{O}_{2}$ and $\mathrm{O}_{2}{ }^{-}$are normal in riboflavin deficiency. However, the liver catalase activity has been reported to be decreased in riboflavin deficiency [45]. Thus, oxidants originating from other tissues may be responsible for enhanced oxidation of lens components [24].

In conclusion, the results presented in this paper suggest that, though there exist conflicting reports in the literature about the role of riboflavin in cataract formation $[1,7-9,46]$, there are a host biochemical changes, including enhanced lipid peroxidation, lowered ascorbic acid levels, and GSH-R activity and alterations in protein profiles in riboflavin deficiency [4], which are commonly associated with cataract. Therefore though riboflavin deficiency per se may not lead to frank cataracts, it is biochemically deleterious to lens metabolism and may lead to lens opacity in cases of prolonged deficiency. Alternatively, in combination with other cataractogenic risk factors, riboflavin deficiency might lead to the accelerated or earlier development of cataract.

The authors gratefully acknowledge Dr. B.S. Narasinga Rao, former director, for constant advice and interest throughout the study. The authors thank Dr. Vittal Rao for ophthalmic examination of the rats and Mr. A. Nadamuni Naidu and T. Prasanna Krishna for their help in statistical analysis of the data. The Council for Scientific and Industrial Research, India, is acknowledged for the award of Senior Research Fellowship to P. Vasanth Rao.

\section{REFERENCES}

1. Day, P.L., Langston, W.C., and O'Brien, C.S. (1931): Cataract and other ocular changes in vitamin C deficiency. Am. J. Ophthalmol, 14, 1005-1009.

2. Bunce, G.E. (1980): Nutrition and cataract, in Advances in Modern Human Nutrition, ed. by Tobin, R.B. and Mehlman, M.A., Pathotox Publishers, INC., Park Forest South, Illinois, pp. 1-31.

3. Bhat, K.S., and Gopalan, C. (1974): Human cataract and galactose metabolism. Nutr. Metabol., 17, 1-8.

4. Bhat, K.S. (1983): Alterations in the lenticular proteins of rats on riboflavin deficient diet. Curr. Eye. Res., 2, 829-834.

5. Reddy, V.N., and Giblin, F.J. (1984): Metabolism and function of glutathione in the lens, in Human Cataract Formation, Ciba Foundation Symposium, Pitman, 106, London, pp. $65-87$. 
6. Augusteyn, R.C. (1981): Protein modification in cataract: Possible oxidative mechanisms, in Mechanisms of Cataract Formation in the Human Lens, ed. by Duncan, G., Academic Press, London, pp. 71-115.

7. Srivastava, S.K., and Beutler, E. (1972): Galactose cataract in riboflavin deficient rats. Biochem. Med., 6, 372-379.

8. Ono, S., Hirano, H., Hamajima, S., and Horiuchi, S. (1981): Effect of riboflavin deficiency on the synthesis of ester forms of riboflavin in the rat lens. J. Nutr. Sci. Vitaminol., 27, 599604.

9. Bhat, K.S., and Rao, P.V. (1987): Changes in lens and erythrocyte glutathione reductase in response to exogeneous flavin adenine dinucleotide and liver riboflavin content of rat on riboflavin deficient diet. Nutr. Res., 7, 1203-1208.

10. Bamji, M.S., and Sharada, D. (1972): Hepatic glutathione reductase and flavin concentrations in experimental deficiency of thiamine and riboflavin in rats. J. Nutr., 102, 443-448.

11. Hissin, P.J., and Hilf, R. (1976): A fluorimetric method for determination of oxidized and reduced glutathione in tissues. Anal. Biochem., 74, 214-226.

12. Sedlak, J., and Lindsay, R.H. (1968): Estimation of total, protein bound, and non-protein sulfhydryl groups in tissue with Ellman's reagent. Anal. Biochem., 25, 192-205.

13. Bhuyan, K.C., Bhuyan, D.K., and Podos, S.M. (1981): Evidence of increased lipid peroxidation of cataracts. IRCS Med. Sci., 9, 126-127.

14. Zannoni, V., Lynch, M., Goldstein, S., and Sato, P. (1974): A rapid micromethod for the determination of ascorbic acid in plasma and tissues. Biochem. Med., 11, 41-48.

15. Selvaraj, R.J., and Bhat, K.S. (1972): Phagocytosis and leucocyte enzymes in protein-calorie malnutrition. Biochem. J., 127, 255-259.

16. Bayoumi, R.A., and Rosalki, S.B. (1976): Evaluation of methods of coenzyme activation of erythrocyte enzymes for detection of deficiency of vitamins $\mathrm{B}_{1}, \mathrm{~B}_{2}$ and $\mathrm{B}_{6}$. Clin. Chem., 22, 327-335.

17. Hochstein, P., and Utley, H. (1968): Hydrogen peroxide detoxification by glutathione peroxidase and catalase in rat liver homogenates. Mol. Pharmacol., 4, 574-579.

18. Goldstein, D.B. (1968): A method for assay of catalase with the oxygen cathode. Anal. Biochem., 24, 431-437.

19. Marklund, S., and Marklund, G. (1974): Involvement of the superoxide anion radical in the autoxidation of pyrogallol and a convenient assay for superoxide dismutase. Eur. $J$. Biochem., 47, 469-474.

20. Lowry, O.H., Rosebrough, N.J., Farr, A.L., and Randall, R.J. (1951): Protein measurement with the Folin phenol reagent. J. Biol. Chem., 193, 265-275.

21. Ono, S., and Hirano, H. (1984): FAD-induced in vitro activation of glutathione reductase in the lens of $\mathrm{B}_{2}$ deficient rats. Curr. Eye Res., 3, 663-665.

22. Spector, A. (1984): The search for a solution to senile cataracts: Proctor lecture. Invest. Opthalmol. Vis. Sci., 25, 130-145.

23. Halliwell, B., and Gutteridge, J.M. (1985): Free Radicals in Biology and Medicine, Oxford, London, Clarendon.

24. Zigler, J.S., Jr., Jernigan, H.M., Jr., Garland, D., and Reddy, V.N. (1985): The effect of "oxygen radicals" generated in the medium on lenses in organ culture: Inhibition of damage by chelated iron. Arch. Biochem. Biophys., 241, 163-172.

25. Bhuyan, K.C., and Bhuyan, D.K. (1984): Molecular mechanisms of cataractogenesis iii. Toxic metabolites of oxygen as initiators of lipid peroxidation and cataract. Curr. Eye Res., 3, 67-81.

26. Srivastava, S.K., and Beutler, E.C. (1973): Cleavage of lens proteins-GSH mixed disulfide by glutathione reductase. Exp. Eye Res., 17, 33-42.

27. Kuck, J.F.R., Yu, N.T., and Askren, C.C. (1982): Total sulfhydryl by Raman Spectroscopy in the intact lens of several species: Variations in the nucleus and along the optical axis during aging. Exp. Eye Res., 34, 23-37.

28. Horiuchi, S., Hirano, H., and Ono, S. (1984): Reduced and oxidized glutathione concentra-

Vol. 6, No. 3, 1989 
tions in the lenses of riboflavin deficient rats. J. Nutr. Sci. Vitaminol., 30, 401-403.

29. Bamji, M.S., and Sharada, D. (1970): Physiological implication of reduced glutathione reductase activity of red blood cells in human ariboflavinosis. Clin. Chim. Acta, 31, 409412.

30. Paniker, N.V., Srivastava, S.K., and Beutler, E. (1970): Glutathione metabolism of the red cells. Effect of glutathione reductase deficiency on the stimulation of hexose monophosphate shunt under oxidative stress. Biochim. Biophys. Acta, 215, 456-460.

31. Rogers, K.M., and Augusteyn, R.C. (1978): Glutathione reductase in normal and cataractous human lenses. Exp. Eye Res., 27, 719-721.

32. Ikemoto, F., and Iwata, S. (1978): Sulfhydryl contents of soluble and insoluble lens proteins in naphthalene and traumatic cataract in rabbits. Ophthalmic. Res., 10, 194-201.

33. Hirano, H., Hamajima, S., Horiuchi, S., and Ono, S. (1983): Effect of $B_{2}$-deficiency on lipid peroxide and its scavenging system in the rat lens. Int. J. Vitam. Nutr. Res., 53, 377-382.

34. Chow, C.K., and Tappel, A.L. (1972): An enzymatic protective mechanism against lipid peroxidation damage to lungs of ozone exposed rats. Lipids, 7, 518-524.

35. McCay, P.B., Gibson, D.D., Fong, K.L., and Hornbrook, K.R. (1976): Effect of glutathione peroxidase activity on lipid peroxidation in biological membranes. Biochim. Biophys. Acta, 431, 459-468.

36. Taniguchi, M., and Hara, T. (1983): Effect of riboflavin and selenium deficiencies on glutathione and its relating enzyme activities with respect to lipid peroxide content of rat livers. J. Nutr. Sci. Vitaminol., 29, 283-292.

37. Yagi, K., Komura, S., Yamauchi, T., Watanabe, I., and Ihara, N. (1986): Lipid peroxides as a possible cause of cataractogenesis. Proc. Int. Soc. For. Eye Res., IV, 74.

38. Nair, V., Cooper, C.S., Vietti, D.E., and Turner, G.A. (1986): The chemistry of lipid peroxidation metabolites: Crosslinking reactions of malondialdehyde. Lipids, 21, 6-10.

39. Bhuyan, K.C., Vaster, R.W.P., Coles, R.S., and Bhuyan, D.K. (1986): Molecular mechanisms of cataractogenesis: IV. Evidence of phospholipid-malondialdehyde adduct in human senile cataract. Mech. Ageing Dev., 34, 289-296.

40. Little, C., and O'Brien, P.J. (1968): An intracellular GSH peroxidase with a lipid peroxide substrate. Biochem. Biophys. Res. Commun., 31, 145-150.

41. Heath, H. (1962): The distribution and possible function of ascorbic acid in the eye. Exp. Eye Res., 1, 326-327.

42. Bondannes, R.S., and Chan, P.C. (1979): Ascorbic acid is a scavenger of singlet oxygen. FEBS Lett., 105, 195-196.

43. Varma, S.D., Kumar, S., and Richards, R.D. (1979): Light-induced damage to ocular lens cation pump: Prevention by vitamin C. Proc. Natl. Acad. Sci. USA., 76, 3504-3506.

44. Kiuchi, K., Nishikimi, M., and Yagi, K. (1980): L-Gulonolactone oxidase activity and vitamin $\mathrm{C}$ status in riboflavin-deficient rats. Biochim. Biophys. Acta, 630, 330-337.

45. Lee, S.S., Ye, J., Jones, D.P., and McCormick, D.B. (1983): Correlation of $\mathrm{H}_{2} \mathrm{O}_{2}$ production and liver catalase during riboflavin deficiency and repletion in mammals. Biochem. Biophys. Res. Commun., 117, 788-793.

46. Hasegawa, Y., and Yagi, K. (1975): Electron microscopic study on the lens of riboflavin deficient albino rat. J. Nutr. Sci. Vitaminol., 21, 395-401. 